Lin W. Revealing the making of OpenStreetMap: A limited account. The Canadian Geographer 2015, 59(1), 69-81.

\title{
Copyright:
}

This is the peer reviewed version of the following article: Lin W. Revealing the making of OpenStreetMap: A limited account. The Canadian Geographer 2015, 59(1), 69-81., which has been published in final form at http://dx.doi.org/10.1111/cag.12137. This article may be used for non-commercial purposes in accordance with Wiley Terms and Conditions for Self-Archiving.

DOI link to article:

http://dx.doi.org/10.1111/cag.12137

Date deposited:

$09 / 12 / 2014$

Embargo release date:

16 October 2016

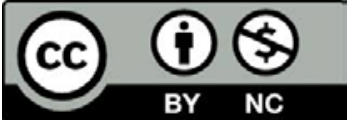

This work is licensed under a Creative Commons Attribution-NonCommercial 3.0 Unported License 


\section{Revealing the making of OpenStreetMap: A limited account}

\section{SHORT TITLE: Revealing the making of OpenStreetMap}

(Published in The Canadian Geographer, ePub ahead of print, http://dx.doi.org/10.1111/cag.12137)

Wen Lin

School of Geography, Politics and Sociology, Newcastle University

Correspondence to: Wen Lin, Room 3.73a, Daysh Building, Claremont Road, School of

Geography, Politics and Sociology, Newcastle University, Newcastle upon Tyne, UK, NE1 7RU, United Kingdom. Email: wen.lin@ncl.ac.uk

Abstract: OpenStreetMap (OSM), an open source mapping platform aiming to provide a free world map by registered users, has often been recognized as one of the prime examples of volunteered geographic information (VGI) construction. This is reflective of the recent exponential growth of user-generated geographic data facilitated by Web 2.0 technologies and location-aware devices. Notable efforts have been taken to investigate OSM developments and associated sociopolitical implications. However, still little is known about those less active contributors who constitute the majority of the contributors or long tail contributors in OSM and many other VGI initiatives. I therefore present an account of the dynamics of OSM mapping practices including these long tail contributors. Based on this investigation, I argue for a broader conceptualization of 'interactivity' in VGI mappings, one that moves beyond a narrow focus on the mapping interface regarding the encounters between these VGI contributors and VGI initiatives. I suggest that this is helpful to better capture these dynamic and heterogeneous 
mapping practices constituting the data and representation in OSM, which in turn may have wider implications for everyday mapping and knowledge production.

Keywords: Volunteered geographic information, OpenStreetMap, everyday mapping, UK

Key messages: 1) This article provides a situated analysis of the mapmaking process in OSM regarding a range of contributors' experiences; 2) This article analyzes social constructions of VGI and OSM in particular through illustrating various moments mapmaking processes with greater attention to experimental knowledge, especially that of the less active contributors; 3 ) This article intends to enrich the discussion on the aspect of interactivity in VGI research. 


\section{Introduction}

The recent explosive growth of user-generated geographic information since the mid-2000s has drawn significant attention from GIS scholars and human geographers (e.g., Elwood et al. 2012). A flowering body of work has sought to interrogate this phenomenon and the associated sociopolitical implications, recognizing the profound impacts on the way geographic information is produced and shared (e.g., Crampton 2009; Elwood 2008; 2009; 2010; Goodchild 2007; 2008; Graham 2010; Haklay et al. 2008; Sui 2008; Zook and Graham 2007). A number of terms have been used to characterize such a phenomenon, including volunteered geographic information (VGI) (Goodchild 2007), neogeography (Turner 2006), and Maps 2.0 (Crampton 2009). I employ the notion of VGI here in this study, emphasizing the aspect of users knowingly contributing geographic information mediated through Web 2.0 technologies and location-aware devices. Influenced by the critical GIS traditions, a growing number of studies have examined how such practices have constituted and facilitated new ways of knowledge production and politics in the context of everyday mapping (e.g., Elwood and Leszczynski 2013; Wilson and Graham 2013; Lin 2013). Two issues are of particular interest here. First, more research is needed on how spatial knowledge is constructed by various everyday mappers in seemingly more mobile, individualized and yet more connected ways (Elwood et al. 2012; Perkins 2013). For example, as Elwood et al. $(2012,366)$ ask, “[w]hat dimensions of a contributor's experiential knowledge can we expect to be included or excluded in a VGI initiative?" Also, "[h]ow do different kinds of social connectivities and interactivities in VGI initiatives shape the content and character of the information that emerges?" I argue that to address these questions and deepen our understanding of VGI, it is important to broaden our conceptualization of interactivity in the 
mapping process, to illustrate processes that involve and constitute contributors' experiential knowledge embedded and produced in VGI initiatives. Related to this, the second issue is that still little is known about those who are less active VGI contributors (Crampton 2009; Elwood et al. 2012). I argue that including less active contributors' experiences would provide a fuller account of the heterogeneous everyday mapping practices and associated knowledge production. Moreover, as I will discuss in greater detail below, these experiences and challenges the less active contributors might have can be more effectively illustrated through a broadening conceptualization of interactivity noted above, which in turn would leave imprints on what kinds of data and representation we might see in VGI initiatives.

Therefore, I seek to contribute to these discussions through exploring these highly diverse, mundane, and quotidian mapping processes through a case of OpenStreetMap (OSM), an open source mapping platform that aims to provide a free world map collectively produced by registered users. Founded in 2004 by Steve Coast, OSM has grown from 3,000 registered users in 2006 to more than one million users a decade later (OpenStreetMap 2013), thus serving as an important site for examining VGI constructions in this study. Researchers have sought to interrogate the role of OSM in mobilizing, facilitating, and representing geographic knowledge production by various amateur mappers (e.g., Eckert 2010; Gerlach 2010; Haklay 2010a; Lin 2011; Mooney and Corcoran 2012; Perkins 2011; 2013; Perkins and Dodge 2008; Zook et al. 2010).

Specifically, one key notion emerged in the discussion of VGI is 'everyday mapping' facilitated by the growing availability of online free and open source mapping platforms and tools (e.g., Elwood 2009; Perkins 2008; 2013; Lin 2013). While many studies have examined how OSM might provide alternative mapping data sources through crowd-sourcing as compared 
to existing authoritative data sources, OSM may also provide possibilities for more mundane and quotidian mappings (Gerlach 2010). Perkins $(2013,4)$ provides an insightful analysis of how OSM can “offer different degrees of (im)mobility," responding to Bruno Latour's notion of maps as ‘immutable mobiles'. As aptly suggested by Perkins (2013), instead of viewing crowd-sourced maps as either immutable or mutable, mapping should be viewed as both, shaped by particular local settings. New forms of knowledge politics in digital activism have also emerged, as explicated by Elwood and Leszczynski (2013). Such knowledge politics embody visual experiences through geovisual artifacts that tend to be highly individualized, interactive, and exploratory. These experiential cartographic representations gain credibility through "practices of transparency, peer verification and witnessing" (ibid, 553). Nonetheless, more research is needed to further investigate how users/authors 'interact' in the context of everyday mapping, especially considering the increasing interactions enabled by this new array of geospatial technologies.

Meanwhile, while there have been notable efforts to investigate how OSM mapping practices might intersect with particular social and cultural conditions (Lin 2011; Eckert 2010), there has not been much research on a variety of contributors regarding their experiences. In particular, detailed accounts of these contributors who only engage occasionally with OSM are lacking. These less active contributors have often been recognized as part of the long tail contributors, referring to the phenomenon that the large majority of users contribute a small proportion of the content in VGI (Crampton 2009; Eckert 2010). While the more active users may have a bigger role in shaping the representation and data construction in these mapping platforms, it is also vital to investigate the experiences of long tail contributors, which can potentially help to understand the heterogeneity of VGI, a key characteristic of VGI. Moreover, 
these accounts may help to understand how long tail contributors might become more active.

As such, drawing upon interviews with OSM mappers in 2013, I suggest that it is important to incorporate multiple dimensions of interactivity in analyzing various OSM mappers' experiences and how such interactivity might influence and constitute knowledge construction in the context of everyday mapping. Research on interactive mapping and geovisualization has highlighted the importance of interactions in cartography and GIS. Yet, this body of work tends to focus on in what ways interactions with the mapping interface might influence effects of cartographic representation. Studies in critical GIS have sought to examine how these highly interactive Web 2.0 technologies have allowed a new level of user participation in geographic data production and dissemination (e.g., Sui et al. 2012) and new forms of politics (Elwood and Leszczynski 2013). I argue for a step further to conceptualize interaction more broadly to incorporate experiences that might reside outside the mapping interface. More specifically, informed by critical GIS and communications studies, I highlight three dimensions of interactivity: user-to-system interactivity, user-to-documents interactivity, and user-to-user interactivity. This broader conceptualization of interactivity in VGI and everyday mapping will contribute to the ongoing efforts to understand the embodied mapping practices and associated politics (e.g., Kitchin and Dodge 2007; Perkins 2013; Gerlach 2013). In particular, I suggest that these forms of interactivity help to constitute more mundane and irregular contributions in OSM, which to some extent resonate with Gerlach's (2013) notion of 'vernacular mapping'. Conversely, these mundane and quotidian mapping practices may in turn influence not only how the landscape is represented, but also how it is imagined. In what follows, I first review relevant literature, focusing on two streams: one is investigating who are the contributors and associated motivations, while the other is the issue of interactivity. I then discuss my methods in greater 
detail before I analyze the empirical data and present a concluding section.

\section{Who are the contributors and why do they contribute?}

Significant attention has been given to investigating who are the VGI contributors and the motivations of these contributors (e.g., Budhathoki 2010; Budhathoki and Haythornthwaite 2013). For example, based on survey results derived from global users and content analysis of the talk pages in OSM, Budhathoki (2010) identifies a number of motivational constructs including self-need, instrumentality of local knowledge, project goal, altruism, social/show off, monetary, and learning. Yet, given the scale of the data measurement and analysis, Budhathoki (2010) also points out that more context-specific studies are needed.

Lin (2011) employs the notion of 'social worlds' to illuminate the 'produsage' process in OSM. Social worlds refer to "networks of regular activity and mutual response whose boundaries are set by lines of communication and participation" (Ulmer 1997, 22). Drawing upon interviews and observations, she identifies four social worlds of these mappers: business social world, government social world, NGO/third sector social world, and individual/local social world. While these participants are diverse themselves and constitute four social worlds, they tend to share a rather strong identity as 'OpenStreetMapper'. As such, a sense of community has played an important role in motivating these contributors. Eckert (2010) identifies three "mobilizational frames," which are "you," "the community," and "the map," through which user-participants have been motivated. In doing so, Eckert (2010) also seeks to go beyond the notion of viewing the user-participant, a term he proposes to illustrate the blurring line between the map producer 
and user, as an individual rational actor. Furthermore, Eckert argues that such a conceptualization of user motivations and what it means to be a user helps to "account for interactions at a more macro scale of multi-user relationships" (ibid, 7). While Lin (2011) draws attention to nuances of various user communities that might be characterized by different world views, Eckert (2010) reveals the importance of investigating complex multi-user interactions in constituting user-participants for OSM mapping. These studies are helpful to gain better understandings of the constructions of OSM. Yet, many of the interviews conducted in these studies took place at the State of the Map conference, the annual meeting of OSM, which might tend to involve those who are more active contributors. To complement this, I thus intend to explore in this study a range of user experiences including occasional mappers by following their experiences of encountering OSM and reflections. This would also allow an opportunity to enrich the discussion on the role of different forms of interactions in constituting everyday mapping practices and knowledge construction.

Another important line of enquiry in critical GIS and cartography is to examine how power relations shape and are reshaped by mapping practices (e.g., Crampton and Krygier 2005). Notable attention has been given to in what ways OSM may empower and disempower communities and individuals. Gerlach (2010) conceptualizes OSM as 'vernacular mapping' rather than a counter-mapping project or an indigenous project. Caquard (2011) views OSM as a form of 'new digital grid map,' or a crowd-sourced base map. 'Vernacular mappings' stress the everyday mode of mapping that tell "open-ended and inconclusive stories" (Gerlach 2010, 167), while the 'new digital grid map' underlines issues of data quality and validity as well as ownership in crowd-sourcing. Also, Stephens (2013) provides an analysis of the gender divide in the volunteers that contribute geographic information through a survey on Internet users 
internationally in the context of OSM and Google MapMaker. She highlights that these VGI contributions, while constitute new ways of data production and interacting with geographic data, tend to derive from specific demographic segments, which embody particular viewpoints that may underpin particular representations and knowledge production. Stephens suggests that inequalities in such user-generated contributions cannot be addressed by the platform alone (ibid). Perkins (2013) also provides a rich account of various "tensions in the new knowledge space" (11).

These studies show that while crowd-sourced mappings such as those through OSM have great potential for empowering both mappers and users, it is also clear that there are variable outcomes and that the active VGI contributors in platforms like OSM tend to represent particular demographic segments (Stephens 2013; Perkins 2013; Crutcher and Zook 2009). This necessitates continuous efforts to examine "the cultural contingency and local construction of places by a multitude of everyday mappers" in order to "understand the newly emerging practices and ethics of crowd-sourced mapping" (Perkins 2013, 12). I seek to contribute to these discussions through foregrounding a range of OSM mappers' experiences, including those mappers who are less active. This investigation allows an in-depth exploration into users' experiences regarding their interactions with the map, the platform, and the 'community', which underlines the notion of 'interactivity' as reviewed below.

\section{Interactivity and everyday mapping}

There have been numerous efforts to conceptualize the notion of interactivity. Two bodies of 
work are particularly relevant here: geovisualization research (e.g., MacEachren and Kraak 1997; Crampton 2002; Roth 2013) and studies on media environments and technologies (e.g., McMillan 2002; Bucy 2004; Richards 2006). Discussions in geovisualization provide important insights into understanding the interactions between the map user and the map interface (e.g., Crampton 2002; Roth 2013). Roth (2013) further suggests that more research on what he calls 'cartographic interaction' is needed, which can complement and enrich existing research that tends to focus on cartographic representation, especially against the backdrop of the transformations of information and communication technologies. Cartographic interaction refers to "how maps are manipulated by the map user" (Roth 2013, 60). The recent emergence of location-based services raises new questions regarding cartographic interaction as compared to conventional desktop-based or browser-based mapping and concerns about privacy (ibid). Nonetheless, as Roth (2013) notes, these discussions in geovisualization and interactive mapping have been largely focused on the 'science' aspect of cartographic interaction, resonating with efforts in information visualization and visual analytics, which tend to focus on the interactions between the mapping interface and the user. In addition, usability research concerning the level of effective cartographic design and map use has investigated the role of mobile technologies and multimedia representation (e.g., Urquhart et al. 2003). While useful, many of these studies in usability research tend to focus on the performance of navigation systems (Dillemuth 2005). I further draw upon insights from research on media environments to illuminate how OSM mappers might interact with the data and mapping conditions more broadly in the context of the emerging everyday mapping practices, which are addressed below.

Debates revolve around addressing interactivity as perceived by users, property of media environments, as well as actual activities (Richards 2006). Richards (2006, 532) proposes to 
view interactivity as "a contextualizing facility that mediates between environments and content and users and enables the generation of further content" (emphasis original). Interactivity, as defined by Richards $(2006,536)$, "facilitates and is an outcome of person/technology/world to person/technology/world contact." In this way, interactivity is both a property and activity (ibid).

Moreover, the notion of interactivity has been widely recognized as one of the key characteristics of new media (Macnamara 2010; van Dijk 1999). It can be defined through three dimensions: user-to-system interactivity, user-to-documents interactivity, and user-to-user interactivity (Macnamara 2010). As pointed out by Macnamara (2010), the user-to-system interactivity is similar to person-to-machine interaction, a significant component in the human computer interaction field. User-to-documents interactivity allows user-generated content production rather than merely consuming the content (Macnamara 2010). In particular, the userto-user interactivity and the user-to-documents interactivity are seen as the significant features of Web 2.0 (ibid) that enable users to become produsers (Bruns 2008).

However, with a few exceptions (e.g., Elwood and Leszczynski 2013; Wilson 2012), there has not been much explicit discussion of interactivity in the context of VGI. In their study of how activists and NGOs encounter in the geoweb with new spatial media may constitute new forms of knowledge politics, Elwood and Leszczynski (2013) explicate how interactivity in this context entails a way of exploration and knowing. Such a way of knowing underpins the two new dimensions of knowledge politics: a resituating of geovisual epistemologies and a reworking of expertise, as compared to conventional modes of engagements with GIS (ibid). Zook and Graham $(2007,1326)$ suggest the notion of 'DigiPlace' to analyze the "mixing of code, data and physical place" shown through Google Maps and Google Earth. In particular, DigiPlace has three new senses regarding the power of maps in shaping "interactions and experiences with 
place": automatically produced visibility, highly individualized construction, and dynamism (ibid, 1327). While the issue of interactivity is not directly addressed in DigiPlace, it plays an important role in these three senses, which is facilitated and shaped by codes and enacted by users of cyberspace.

Building upon these studies, an exploration of the aspect of interactivity in VGI research could be helpful to further understand how mediated experience and everyday mapping take place. This article serves as an initial attempt to illustrate these interactions through the OSM mappers' experiences intersecting with the dimensions of user-to-system, user-to-user, and userto-documents interactivity. Before I proceed with the empirical analysis, I discuss the methods used for this research.

\section{Methods}

A number of studies (e.g., Haklay et al. 2008) have provided detailed accounts of the major social and technological transformations regarding the emergence of OSM. Here, to understand and reveal how particular places might be mapped and constructed through OSM, I invited those who might have contributed to mapping Newcastle upon Tyne (Newcastle hereafter) in the UK for interview. This approach was used to provide illustrative cases rather than representative ones in this project. Specifically, these potential interviewees were derived from the results shown from a keyword search of "Newcastle" in OSM. The search results showed edits intersecting with the city, from which user accounts and their correspondent editing history were displayed. I then sent out email invitations using the "message" function in OSM to the contributors found 
from the keyword search. While the keyword search was focused on Newcastle, responses regarding my interview invitation show that many mappers are located outside Newcastle.

In total, I conducted twelve interviews in the UK based on the responses received, of which one was conducted via email. Each of the face-to-face semi-structured interviews lasted from thirty minutes to one hour. The email interview is much shorter than those conducted faceto-face. Nonetheless, this interview still provides important information regarding that particular contributor's experience. The leading interview questions aim to elicit information about interviewees' experiences of using and contributing to OSM mapping, including, for example, how they learn about OSM, major purposes of using and contributing to OSM, processes of and difficulties in providing geographic user-generated data, types of data interested and generated, experiences of attending related workshops and mapping parties, factors recognized influencing such practices, and opinions about the role of OSM and other online mapping platforms. The interviews were then transcribed and coded to identify major themes.

Eleven participants are male and only one participant is female. The overall characteristics of these interview participants resonate with the existing findings regarding OSM contributors (Haklay et al. 2008; Budhathoki 2010): at least nine of them have a college degree, dominantly male, and also exhibit a long tail effect with around interviewees contributing a limited number of records while a few others contributing a disproportionally higher number of records. For example, two interviewees contributed less than 10 edits, while the most active contributor in this study had more than 15,000 edits. These interviewees come from different backgrounds including working for local government, educational institutions, private sector (ranging from software engineering to part-time work in a restaurant), as well as grassroots organization such as hackerspace. 
These cases derived from the interviews are necessarily limited with respect to the number of participants involved in this study, as compared to the number of existing OSM contributors and users. However, I argue that these cases provide in-depth knowledge about in what ways OSM participants interact with, contribute to, remake, and re-appropriate OSM.

\section{Understanding the making of OSM - a limited account}

In this section, I discuss these mapping experiences roughly in a progressive manner starting from when the participants learned about OSM regarding the overall process in which they participate in the making of OSM, although it may not be a linear process. In particular, I illustrate these OSM contributors' encounters with OSM through the three dimensions of interactivity discussed earlier: user-to-user interactivity, user-to-documents interactivity, and user-to-systems interactivity. With this, I argue that we need to go beyond the mere focus on interface design in GIScience research. While a number of studies in critical GIS have sought to reveal the sociopolitical dimension of various users' interactions with these visualizations (e.g., Elwood and Leszesnski 2013; Parks 2009), the focus still tends to be on the digital system, or what Elwood and Leszesnski (2013) highlight as 'framing'. I show that OSM contributors not only interact with the mapping platform itself, but also engage with other assemblages and actors such as exemplified by some users' interacting with videos of the State of the Map conference for information exchange.

Initial interactions with OSM 
Users' ways of learning about OSM might intersect notably with how OSM has grown and been developed, especially considering the influence of media environments and social conditions. The interviewees range from those getting involved at an early stage of OSM development to those who have learned about it as recently as 2013. With respect to how the interviewees began to know about OSM, around half of them learned about it from the Web. More specifically, they participated in the following three types of activities and discovered OSM: searching the Web about mapping (three interviewees), listening to technology related podcasts (one interviewee), and looking for information about GPS usage (one interviewee). As such, these online activities tend to be technology oriented, mainly from those who have obtained a certain level of experiences working with information technologies (IT). Another way of learning about OSM is from friends. In particular, two interviewees knew about OSM through Peter Miller, who cofounded ITO World, a company that uses OSM data and also engages in developing tools to facilitate collaboration among OSM contributors for mapping. In this case, these interviewees are those with an IT background or related professional background. Two interviewees did not remember how they heard about OSM. Lastly, Interviewee A learned about OSM from a book on maps. There is also a case of starting to notice OSM from discussions about apps for navigation in smartphones. As such, these cases show that the Web has played a significant role for the interviewees to know about OSM, which is perhaps not surprising. It is also important that personal communications or word of mouth also plays a role.

Yet, this also shows a range of ways in which knowledge of VGI and the geoweb might travel and disseminate. Those who found out OSM from the Web could be identified as a form of user-to-system interactivity, where the system here is a particular part of the vast cyberspace that tends to focus on technology development and usage. The word-of-mouth way of information 
dissemination would be a form of user-to-user interactivity. Yet, such user-to-user interactions may also be most likely to be mediated through the Web, such as email communications. For example, Interviewee B, an active contributor, noted that he was invited by Peter Miller to contribute to OSM after Peter Miller saw his geotagged photos on Flickr. However, he had not met Peter Miller prior to this email encounter. The encounters with relevant books and apps, while presenting two very different ways of interaction, can be identified as a form of user-todocuments interactivity. The interaction with books may resemble a traditional author-audience relationship regarding knowledge dissemination, while the interaction with apps is characteristic of Web 2.0 technologies, in which the line between the author and the audience is increasingly blurred.

\section{Getting started with OSM editing}

One common theme emerged regarding why the interviewees contribute to OSM is that features in their neighborhood or close to their neighborhood are not on the map or not appropriately mapped, as noted by eight interviewees. Two interviewees explicitly acknowledged that they embrace the notion of open data and 'giving back' to the community as part of their motivations, while another two interviewees noted that they first started from a technical perspective such as exploring how this process might work. This is in support of the existing findings that local knowledge and pride play an important role in motivating VGI contributors (Budhathoki 2010).

There is a varied level of interactions regarding when they start to contribute data to OSM. In this study, it is the interviewee (Interviewee C) who just learned about OSM most recently that started to add some features right away. He did this through using an app in his 
phone. He works in the housing department of a city council close to Newcastle, and he has working experiences with mapping. It could also be argued that apps in smartphones have played a role in facilitating such an interaction, which is much more mundane and easily accessible. As such, this form of interactivity is highly individualized and casual, reflecting both the user-tosystem (the system being the app) and user-to-documents (the documents being the map and its content) dimensions. Yet, this is also accompanied by this particular interviewee's familiarity with GIS and mapping, as he noted, which makes him feel quite comfortable to begin this process of contributing to OSM quickly.

However, for at least seven interviewees, there is a gap between the time they learned about OSM and the time they actually started to contribute to the editing. This gap could be more than one year. Reasons for this include a sense of uncertainty and fears of making mistakes. Another factor is a lack of appropriate devices such as GPS or smartphones. Interviewee D noted that she did not contribute until she owned a smartphone. The availability of aerial imagery such as those provided by Yahoo! in 2006 and Bing in 2010 has also significantly propelled the users to contribute to the map, especially for those who are not familiar with working with GPS tracks.

There is also a varied level of easiness regarding the process of learning how to contribute. Some interviewees noted that it was quite straightforward even though they might not start the editing process right away, while some others noted that they were struggling at the beginning. For those who found it difficult at first, there were several issues. First, one early contributor, Interviewee E, a quite active contributor (Figure 1), noted that figuring out how to convert and upload the GPS tracks from his phone at the early stage was not very easy. This was before the availability of the aerial imagery. However, the recent availability of various interfaces provided by mobile devices did not seem to greatly improve his experience of 
contributing to OSM. He commented that sometimes there were too many ways for OSM mapping that he became less consistent with the edits.

Interviewee F, a less active contributor (Figure 1), commented that while there were many help documents out there, he found it quite difficult to locate those that could directly address the questions he had. Interviewee $\mathrm{C}$, who started his first contribution quickly, commented that it was more about identifying the characteristics of the data that was challenging, for example, the classification of certain features. He mapped an office building, and thought of tagging it as so. However, he later realized that he should have looked for the category of amenities first, which contains the category of buildings.

Existing accounts of OSM have not addressed these moments of fears and uncertainty, which would usually not be shown on the talk pages or wiki pages either. Some aspects have been alluded to in Lin's (2011) study, but they were discussed more in terms of considering rules of mapping. The fear of making mistakes in the mapping process and messing up with important information felt by some contributors can also be seen as an intersection of the user-to-system interactivity and user-to-documents interactivity. On the one hand, mapping in a digital and shared system such as OSM could still be intimidating for many beginners and those without training in conventional cartography or GIS. This could perhaps underpin these users' view about OSM serving as a 'digital grid map' (Caquard 2011). On the other hand, the user-todocuments interactivity adds another dimension to these OSM mapping processes, as some may have gradually established their own ways of mapping through trial and error or looking up for help documents, the latter of which also lends itself to the question of community. Such practices can also be linked to the notion of 'vernacular mappings' (Gerlach 2010). 
The question of community

Notable attention has been paid to the implications of VGI and the geoweb for community in the context of participatory mapping (e.g., Tulloch 2007; Elwood 2008; Lin 2013). In the case of OSM, it has been suggested that mapping parties as well as discussions through mailing lists, forums and wiki pages have facilitated community building for OSM contributors (e.g. Poore and Wolf 2012). Through a quantitative analysis of the case in Greater London, Hristova et al. (2013) suggest those who attend mapping parties tend to contribute more edits than usual. Lin's (2011) analysis helps to illustrate the complexities of community building and identity construction in OSM. Nonetheless, still there have not been many accounts to illustrate these community building processes as well as how different communities might intersect with and differ from one another.

The interviewees' experiences with respect to interactions to other users and communities vary quite significantly in this study. First, there are four interviewees who participated in the mapping parties and found these practices helpful for several reasons such as making plans for future focus of the local area, networking, and learning new things in mapping. These experiences demonstrate the role of mapping parties in community building, which has been well recognized (e.g., Poore and Wolf 2012; Eckert 2010). Yet, these mapping parties also vary themselves with respect to their composition and scale. Some communities are much more active than others, ranging from monthly meetings to just occasional occurrences. These interviewees participated in mapping parties also tend to show a high level of user-to-user interactivity in their mapping practices.

Meanwhile, eight interviewees have not participated in any offline gatherings such as 
mapping parties. Yet, they may actively participate in the online community in various ways. For example, Interviewee $\mathrm{G}$ discussed how his contribution to the cycling paths could help the locals as well as himself. With this acknowledgement, there was a community in mind when he mapped these cycling paths. There is also a community beyond the local area where this interviewee resides. While not attending any of the State of the Map meetings, he was attentive to videos of the talks delivered at these meetings. He noted that by listening to these clips, he could get a sense of what was going on, or how OSM might be used by others. Interviewee E considered his contribution to OSM as more of an individual practice; consequently, he did not think attending the mapping parties would be important for his motivation. Yet, he paid attention to communications in the mailing list, which is echoed by another three interviewees. In contrast, interviewee F commented that there was not a sense of local community and that there were many registered users who simply come and go. He also raised his concern that it was frightening to him that one could possibly delete the whole map. Therefore, although only four interviewees have attended at least one mapping party, the comments noted above show that there are various virtual communities perceived and actively constructed in these mapping practices. In this way, these mapping practices tend to be revolved more around user-todocuments (the 'documents' being video clips, contents of the map, etc.) interactivity.

These cases show contradictory accounts regarding the role of community in OSM, or more precisely, different kinds of communities. It is also evident that one may participate in multiple communities at different levels. Among these various communities, a few themes with a more significant identity attachment emerged. One theme is the comments that OSM edits and contributions are a bit like a game. It may become addictive, as noted by interviewee $\mathrm{D}$. This interviewee also shows how a playful way of engaging participants might work in this context 
such as the example of the 'MapATag' game (Figure 2). This game is provided by

Wheelmap.org, an online platform which helps to identify and map wheelchair-accessible places using OSM as the map service. In MapATag, users might add a tag or edit an existing tag of a particular place and assessing its wheelchair accessibility. Users would earn points and badges and the data created in this process would be recorded on Wheelmap, which in turn can be displayed in OSM. Such practices might also be influenced by hacker culture, characterized by playfulness in these mapping practices, reflective of user-to-documents interactivity. A second theme is that many of them also monitor the edits by others, paying close attention to the data quality in this respect. This is indicative of user-to-user interactivity. These dimensions of interactivity necessarily overlap to some extent. Future research is needed to provide more detailed accounts of how these various communities might evolve across space and time. For example, McConchie (2013) examines OSM contributors who maintain OSM edits. Through extracting editing records from the OSM database, McConchie (2013) reveals thought-provoking profiles regarding how these map practices might change over time in different cities, which can be thought of as revealing user-to-user interactivity. More research on some contributors' experiences in relation to these profiles of broader changes would provide complementary insights into understanding how the making of OSM takes place in different geographic and temporal contexts.

\section{Discussions and conclusions}


In this article, I have focused on illustrating various moments of negotiations and struggles in the OSM mapping process. In many ways, these negotiations and difficulties raised by my interviewees can be seen as part of the usability issues of OSM interface and associated process of mapping (e.g., Haklay 2010b; Nielsen and Loranger 2006). These include issues of different levels of ease interacting with the mapping interfaces and using different mapping tools and data collection devices in relation to OSM, which might also resonate with some existing studies in mobile cartography (e.g., Urquhart et al. 2003). However, through revealing these struggles and moments, I also seek to illuminate further the making of OSM as a highly heterogeneous process and "strongly contested in practice" (Perkins 2013, 7). Here, I do not intend to provide a comprehensive history of how OSM has evolved since its inception in 2004. Rather, drawing upon insights from critical GIS research and discussions of interactivity from geovisualization research and communications studies, I aim to present a situated analysis of the various dimensions of interactivity manifested in these mapping moments that constitute the constructions of OSM across space and time.

These moments necessarily intersect with broader technological transformations and sociopolitical conditions (e.g., Haklay et al. 2008; Elwood 2008). For example, the availability of certain devices and tools for OSM editing has played a key role for many interviewees. Technological backgrounds also play a role. Furthermore, foregrounding these moments of mapmaking in the everyday mapping context serves as a helpful illustration of how 'vernacular mappings' (Gerlach 2010) intersect with the mode of 'new digital grid maps' (Caquard 2011), as noted earlier.

With this study, I call for more attention to various modes of interactivity in the process of using, making sense and building of OSM. I also contribute to the largely unexplored area of 
long tail contributors in VGI research. I argue that the three dimensions of interactivity help to crystalize the possibilities and challenges many practitioners might encounter in VGI initiatives, in which the technological and the social systems are mutually constituted. In his analysis of Web topology regarding the distribution of links, Benkler $(2006,254)$ points out that there could be active interlinked subclusters within the long tail, which include some relatively highvisibility nodes that can "serve as points of transfer to larger clusters". I show that there are efforts from some of the long tail contributors interacting with actors and processes situated at multiple levels, which can potentially serve as a foundation for a more active subcluster. Experiences from Interviewees D and G might indicate such possibilities, with their more constant 'user-to-documents' and 'user-to-user' interactivities. However, I also show various challenges, equally can be reflected in these different modes of interactivity, such as experiences from Interviewee F.

More research is needed to further illustrate these various interactions and moments across space and time, given the increasing growth of OSM users and employment of OSM data in a wide range of fields. Also, there is still little research on comparative perspectives. Future research may also employ more mixed-methods approaches, such as network analysis and visualization as well as surveys, interviews, and document analysis to reveal the social construction of OSM over time. In this regard, this article serves as an initial attempt to engage with documenting the social construction of VGI from several dimensions such as insights from critical GIS and cartography, the writing on open source software movement, media and cultural studies, the affective dimension of map-making, and the political economic dimension.

\section{Acknowledgements}


I am grateful to the interviewees for sharing their experiences. I would like to thank the editor and three anonymous reviewers for their detailed and invaluable comments that help to strengthen the article. This research was supported by the Faculty Research Fund from Newcastle University. Any errors are the responsibility of the author.

\section{References}

Benkler, Y. 2006. The Wealth of Networks: How Social Production Transforms Markets and Freedom. London: Yale University Press.

Bucy, E.P. 2004. Interactivity in Society: Locating an Elusive Concept. The Information Society 20(5): 373-83.

Bruns, A. 2008. Blogs, Wikipedia, Second Life, and Beyond: From Production to Produsage. New York, NY: Peter Lang.

Budhathoki, N. 2010. Participants' motivations to contribute geographic information in an online community. $\mathrm{PhD}$ dissertation, University of Illinois at Urbana-Champaign.

Budhathoki, N., and C. Haythornthwaite. 2013. Motivation for Open Collaboration Crowd and Community Models and the Case of OpenStreetMap. American Behavioral Scientist 57(5): 548575.

Caquard, S. 2011. Cartography I: Mapping narrative cartography. Progress in Human Geography 37(1): 135-144.

Crampton, J. 2002. Interactivity Types in Geographic Visualization. Cartography and Geographic Information Science 29(2): 85-98.

-. 2009. Cartography: maps 2.0. Progress in Human Geography 33: 91-100.

Crampton, J., and J. Krygier. 2005. An introduction to critical cartography. ACME: An 
International E-Journal for Critical Geographies 4:11-33.

Crutcher, M., and M. Zook. 2009. Placemarks and waterlines: Racialized cyberscapes in postKatrina Google Earth. Geoforum 40(4): 523-534.

Dillemuth, J. 2005 Map Design Evaluation for Mobile Display. Cartography and Geographic Information Science 32(4): 285-301.

Dodge, M., and R. Kitchin. 2007. 'Outlines of a world coming into existence': pervasive computing and the ethics of forgetting. Environment and Planning B: Planning and Design 34(3): $431-445$.

Eckert, J. 2010. Tropes 2.0: Mobilization in OpenStreetMap. Master's thesis, University of Washington.

Elwood, S. 2008. Volunteered geographic information: future research directions motivated by critical, participatory, and feminist GIS. GeoJournal 72:173-183.

—. 2009. Geographic Information Science: new geovisualization technologies - emerging questions and linkages with GIScience research. Progress in Human Geography 33: 256-263

-. 2010. Geographic Information Science: emerging research on the societal implications of the geospatial web. Progress in Human Geography 34: 349-357.

Elwood, S., Goodchild, M., and D. Sui. 2012. Researching volunteered geographic information (VGI): Spatial data, geographic research, and new social practice. Annals of the Association of American Geographers 102(3): 571-590.

Elwood, S., and A. Leszczynski. 2013. New spatial media, new knowledge politics. Transactions of the Institute of British Geographers 38(4): 544-559.

Gerlach, J. 2010. Vernacular mapping, and the ethics of what comes next. Cartographica 45(3): $165-168$. 
—. 2013. Lines, contours and legends: Coordinates for vernacular mapping. Progress in Human Geography. 1-18. doi: 10.1177/0309132513490594.

Goodchild, M. 2007. Citizens as sensors: The world of volunteered geography. GeoJournal 69: 211-221.

—. 2008. Commentary: whither VGI? GeoJournal 72: 239-244.

Graham, M. 2010. Neogeography and the palimpsests of place. Tijdschrift voor Economische en Sociale Geografie 101: 422-436.

Haklay, M. 2010a. How good is volunteered geographical information? A comparative study of OpenStreetMap and Ordnance Survey datasets. Environment and Planning B: Planning and Design 37(4): 682-703.

—. 2010b. Haiti - Further comparisons and the usability of geographic information in emergency situations. http://povesham.wordpress.com/2010/01/29/haiti-\%E2\%80\%93-further-comparisonsand-the-usability-of-geographic-information-in-emergency-situations/. Accessed January 15, 2014.

Haklay, M., Singleton, A., and C. Parker. 2008. Web mapping 2.0: The Neogeography of the GeoWeb. Geography Compass 2(6): 2011-2039.

Hristova, D., G. Quattrone1, A. Mashhadi, and L. Capra. 2013. The Life of the Party: Impact of Social Mapping in OpenStreetMap. Proceedings of the AAAI International Conference on Weblogs and Social Media. Association for the Advancement of Artificial Intelligence.

Kitchin, R., and M. Dodge. 2007. Rethinking maps. Progress in Human Geography 31:331-344. Lin, W. 2013. Volunteered geographic information and networked publics? Politics of everyday mapping and spatial narratives. GeoJournal, doi: 10.1007/s10708-013-9490-1.

Lin, Y. 2011. A qualitative enquiry into OpenStreetMap making. New Review of Hypermedia 
and Multimedia 17(1): 53-71.

MacEachren, A., and M.-J. Kraak. 1997. Exploratory cartographic visualization: Advancing the agenda. Computers \& Geosciences 23(4): 335-343.

Macnamara, J. 2010. Public communication practices in the Web 2.0-3.0 mediascape: The case for PRevolution. PRism 7(3).

McConchie, A. 2013. From Wiki Gardening to Map Gardening Analyzing Contribution Patterns in OpenStreetMap. http://vimeopro.com/openstreetmapus/state-of-the-map-us2013/video/68097490

McMillan, S. 2002. A Four-Part Model of Cyber-interactivity: Some Cyber-places are More Interactive Than Others. New Media \& Society 4(2): 271-91.

Nielsen, J., and H. Loranger. 2006. Prioritizing web usability. Berkeley: New Riders Press. OpenStreetMap. 2013. History of OpenStreetMap. http://wiki.openstreetmap.org/wiki/History_of_OpenStreetMap. Perkins, C. 2008. Cultures of map use. The Cartographic Journal 45:150-158.

—. 2011. Researching mapping: methods, modes and moments in the (im)mutability of OpenStreetMap. Global Media Journal-Australian Edition 5(2): 1-12.

—. 2013. Plotting practices and politics: (im)mutable narratives in OpenStreetMap. Transactions of the Institute of British Geographers. doi: 10.1111/tran.12022.

Perkins, C., and M. Dodge. 2008. The potential of user-generated cartography: a case study of the OpenStreetMap project and Mapchester mapping party. North West Geography 8(1): 19-32. Poore, B., and E. Wolf. 2012. Metadata Squared: Enhancing Its Usability for Volunteered Geographic Information and the GeoWeb. In Crowdsourcing Geographic Knowledge: Volunteered Geographic Information (VGI) in Theory and Practice, ed. D. Sui, S. Elwood, S. 
and M. Goodchild. London, UK: Springer, 43-64.

Richards, R. 2006. Users, interactivity and generation. New Media Society 8: 531-550.

Roth, R.E. 2013. Interactive maps: What we know and what we need to know. The Journal of Spatial Information Science 6: 59-115.

Schuurman, N. 2004. Databases and bodies: A cyborg update. Environment and Planning A 36: $1337-1340$.

Stephens, M. 2013. Gender and the GeoWeb: divisions in the production of user-generated cartographic information. GeoJournal. doi: 10.1007/s10708-013-9492-z

Sui, D. 2008. The wikification of GIS and its consequences: Or Angelina Jolie's new tattoo and the future of GIS. Computers, Environment and Urban Systems 32: 1-5.

Sui, D., M. Goodchild, and S. Elwood. 2012. VGI, the exaflood, and the growing digital divide. In Crowdsourcing Geographic Knowledge: Volunteered Geographic Information (VGI) in Theory and Practice, ed. D. Sui, S. Elwood, S. and M. Goodchild. London, UK: Springer, 1-12. Tulloch, D. 2007. Many, many maps: empowerment and online participatory mapping. First Monday 12(2).

http:/firstmonday.org/htbin/cgiwrap/bin/ojs/index.php/fm/article/view/1620/1535.

Ulmer, J. T. 1997. Social Worlds of Sentencing: Court Communities Under Sentencing Guidelines. New York, US: State University of New York Press.

Urquhart, K., W. Cartwright, S. Miller, K. Mitchell, C. Quirion, and P. Benda. 2003. Ensuring useful cartographic representations in location-based services. In: Proceedings of the 21 st International Cartographic Conference, Durban, South Africa. pp. 2591-2602. van Dijk, J. 1999. The network society: Social aspects of new media. London, UK: Sage. Wilson, M.W. 2012. Location-based services, conspicuous mobility, and the location-aware 
future. Geoforum 43(6): 1266-1275.

Wilson, M.W., and M. Graham. 2013. Situating neogeography. Environment and Planning A 45(1): 3-9.

Zook, M., and M. Graham. 2007. The creative reconstruction of the internet: Google and the privatization of cyberspace and Digiplace. Geoforum 38: 1322-1343.

Zook, M, M.Graham, T. Shelton, and S. Gorman. 2010. Volunteered geographic information and crowdsourcing disaster relief: a case study of the Haitian earthquake. World Medical \& Health Policy 2(2): 7-33.

\section{Figure 1}

Screenshots of OSM edits by Interviewees E (top) and F (bottom) in a heat map form generated by 'Your OSM Heat Map'(http://yosmhm.neis-one.org/)

\section{Figure 2}

Screenshot of "MapATag" 